Original Paper (Invited)

\title{
Dynamic Analysis of Francis Runners - Experiment and Numerical Simulation
}

\author{
Stefan Lais ${ }^{1}$, Quanwei Liang ${ }^{1}$, Urs Henggeler ${ }^{1}$, Thomas Weiss ${ }^{1}$, \\ Xavier Escaler $^{2}$ and Eduard Egusquiza ${ }^{2}$
}

\author{
${ }^{1}$ ANDRITZ HYDRO Ltd. Zurich \\ Hardstrasse 319, 8005 Zurich, Switzerland \\ stefan.lais@andritz.com, quanwei.liang@andritz.com, urs.henggeler@andritz.com, \\ thomas.weiss@andritz.com \\ ${ }^{2}$ Technical University of Catalonia (CDIF-UPC) \\ Av. Diagonal 647, 08028 Barcelona, Spain \\ escaler@mf.upc.edu, egusquiza@mf.upc.edu
}

\begin{abstract}
The present paper shows the results of numerical and experimental modal analyses of Francis runners, which were executed in air and in still water. In its first part this paper is focused on the numerical prediction of the model parameters by means of FEM and the validation of the FEM method. Influences of different geometries on modal parameters and frequency reduction ratio (FRR), which is the ratio of the natural frequencies in water and the corresponding natural frequencies in air, are investigated for two different runners, one prototype and one model runner. The results of the analyses indicate very good agreement between experiment and simulation. Particularly the frequency reduction ratios derived from simulation are found to agree very well with the values derived from experiment. In order to identify sensitivity of the structural properties several parameters such as material properties, different model scale and different hub geometries are numerically investigated. In its second part, a harmonic response analysis is shown for a Francis runner by applying the time dependent pressure distribution resulting from an unsteady CFD simulation to the mechanical structure. Thus, the data gained by modern CFD simulation are being fully utilized for the structural design based on life time analysis. With this new approach a more precise prediction of turbine loading and its effect on turbine life cycle is possible allowing better turbine designs to be developed.
\end{abstract}

Keywords: Modal analysis, fluid structure interaction, rotor-stator interaction, harmonic response analysis, instationary CFD.

\section{Introduction}

Dynamic loads on the components of water turbines are of increasing importance for the operators of hydro power plants, for several reasons. Firstly, higher flow rate and power output are major objectives in many modernisation projects, leading to a higher loading of the components and to altered vibration behaviour of the machine. Secondly, the costs of a machine are reduced by increasing the specific speed of a turbine as well as by reducing weight and optimising the use of material. Thirdly, the requirements of the electricity market for quick response lead to more extreme load changes, starts and stops and to frequent stand-by operation thereby increasing the dynamic load of the machines. All these requirements can be safely fulfilled only if the machine components are optimised with respect to both static and dynamic loading in the design phase. Accordingly, turbine manufacturers are improving the numerical methods for prediction and analysis of the dynamic load of the machines in the design phase.

For a comprehensive life cycle analysis in the design phase two different simulation methods are being further developed, validated and connected: Firstly, the structural analysis with the finite element method (FEM) is applied to predicting modal parameters and natural frequencies of a Francis runner in water. This method as well as validation examples are presented in the first part of this paper. Secondly, the unsteady flow and pressure field is predicted by means of time dependent CFD simulations of the entire turbine including stay vanes, guide vanes and runner. The resulting dynamic load acting on the runner surfaces are 
then transferred to the FEM based harmonic response analysis for selected frequencies which have been identified as being critical. Such a harmonic response analysis is presented in the second part of the paper for a high head Francis runner. It will be shown that with this procedure the data gained by modern CFD simulation can be fully utilised for the structural design based on life time.

\section{Methodology}

In the first and the second part of the work modal analysis was carried out for two different Francis runners (A and B), a cast prototype and a segmented model runner, while for the harmonic response analysis and CFD simulation in the third part of this study a high head Francis runner (C) was chosen because the exciting forces are higher compared to a low head runner.

The following table shows a summary of the defining parameters for the runners:

Table 1 Defining runner parameters

\begin{tabular}{|c|c|c|c|c|c|c|c|}
\hline Runner & $\begin{array}{c}\text { Runner } \\
\text { type }\end{array}$ & $\begin{array}{c}\text { Speed } \\
\text { number } \\
\mathrm{n}_{\mathrm{ED}}[-]\end{array}$ & $\begin{array}{c}\text { Number } \\
\text { of blades } \\
\mathrm{z}_{2}[-]\end{array}$ & $\begin{array}{c}\text { Outlet } \\
\text { diameter } \\
\mathrm{D}_{2}[\mathrm{~mm}]\end{array}$ & $\begin{array}{c}\text { Material } \\
\text { density } \\
\rho\left[\mathrm{kg} / \mathrm{m}^{3}\right]\end{array}$ & $\begin{array}{c}\text { Young's } \\
\text { modulus } \\
\mathrm{E}[\mathrm{GPa}]\end{array}$ & $\begin{array}{c}\text { Poisson's } \\
\text { ratio } \\
v[-]\end{array}$ \\
\hline $\mathrm{A}$ & Prototype & 0.34 & 15 & 1300 & 7700 & 206 & 0.3 \\
\hline $\mathrm{B}$ & Model & 0.39 & 15 & 364 & 8600 & 90 & 0.3 \\
\hline $\mathrm{C}$ & Prototype & 0.18 & 17 & 1800 & 7700 & 206 & 0.3 \\
\hline
\end{tabular}

For the analyses the following parameters are characteristic:

- Nodal diameter mode (ND): The nodal diameter refers to the appearance of a geometry (e.g. a disk) vibrating in a certain mode. These mode shapes contain lines of zero out-of-plane displacement which cross the entire disk, as shown in Fig. 1. As will be seen later, these modes are characteristic for analyzing turbine runners. To give an example for the notation example, the expression ND3-1 refers to the first occurring mode shape with 3 nodal lines. The identifier "- 1 " is a counter and does not describe the mode shape.

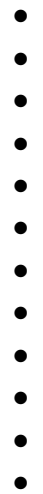

- Operating deflection shape (ODS): the emerging shape of the forced vibration, not to be confused with the mode shape resulting from the modal analysis. If the exciting process is cyclic symmetric, as in case of rotor stator interaction (RSI), the ODS at the same time reveals nodal diameter modes. In case of RSI, the ND modes form the well known travelling pressure wave modes.

- Frequency reduction ratio (FRR): ratio of the natural frequency in water divided by the corresponding natural frequency in air with the same mode shape or, in other words, the same nodal diameter mode ND:

$$
F R R=\frac{f_{\text {nat,water }, N D x}}{f_{\text {nat }, \text { air }, N D x}}
$$

\subsection{Runner A - Modal Analysis}

\section{Experimental modal analysis:}

Runner A is a cast runner, originally supplied in the late sixties. After dismantling the turbine, erosion and light cavitation damages were found, especially near the blade's outlet edges.

The experimental modal analysis of the cast prototype runner A was performed at the ANDRITZ HYDRO laboratory in Zurich. The runner was tested in air and in still water. The runner was supported on the runner flange in upward direction, i.e. with the runner outlet on top, see Fig. 2. Initial tests showed that this setup has no influence on the results and can be regarded as free boundary conditions. Regarding the test in water, the runner was submerged in a rectangular water tank. For excitation, a shaker was mounted on the band outlet between two blades and acted in radial direction both for the measurements in air and in water. 


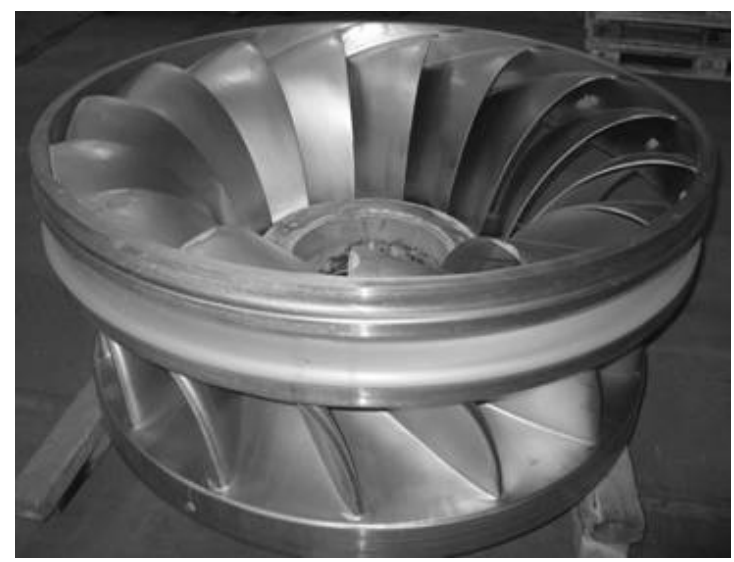

Fig. 2 Runner A, before experimental setup

\section{Numerical modal analysis:}

A finite element analysis of the whole runner firstly surrounded by air and secondly surrounded by water was carried out. The unconstrained finite element model and the corresponding boundary conditions are displayed in Fig. 3. The solid model consists of quadratic tetrahedral elements for the structure and acoustic elements for the fluid.
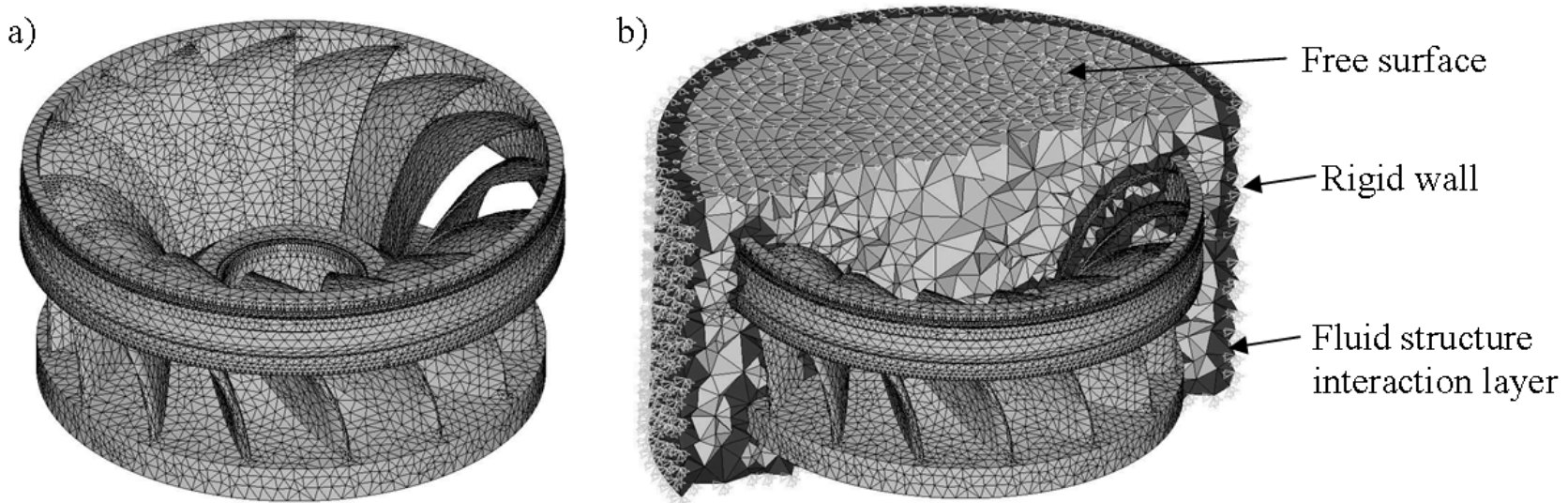

Fig. 3 Runner A - finite element model in a) air and b) water

\subsection{Runner B - Modal Analysis}

\section{Experimental modal analysis:}

Runner B is a modern 15 blade Francis model runner. Its blades are mounted with 3 screws on the band and 2 screws on the crown. In order to approximately create prototype conditions the blades near the trailing edge are fixed with a pin and an additional soldered seam.

The experimental modal analysis of the model runner was carried out at the Center for Industrial Diagnostics (CDIF) at the Technical University of Barcelona (UPC). The runner was tested firstly in air and secondly, in still water by being submerged in a rectangular water tank. In both cases the runner was hung upside down as shown in Fig. 4.
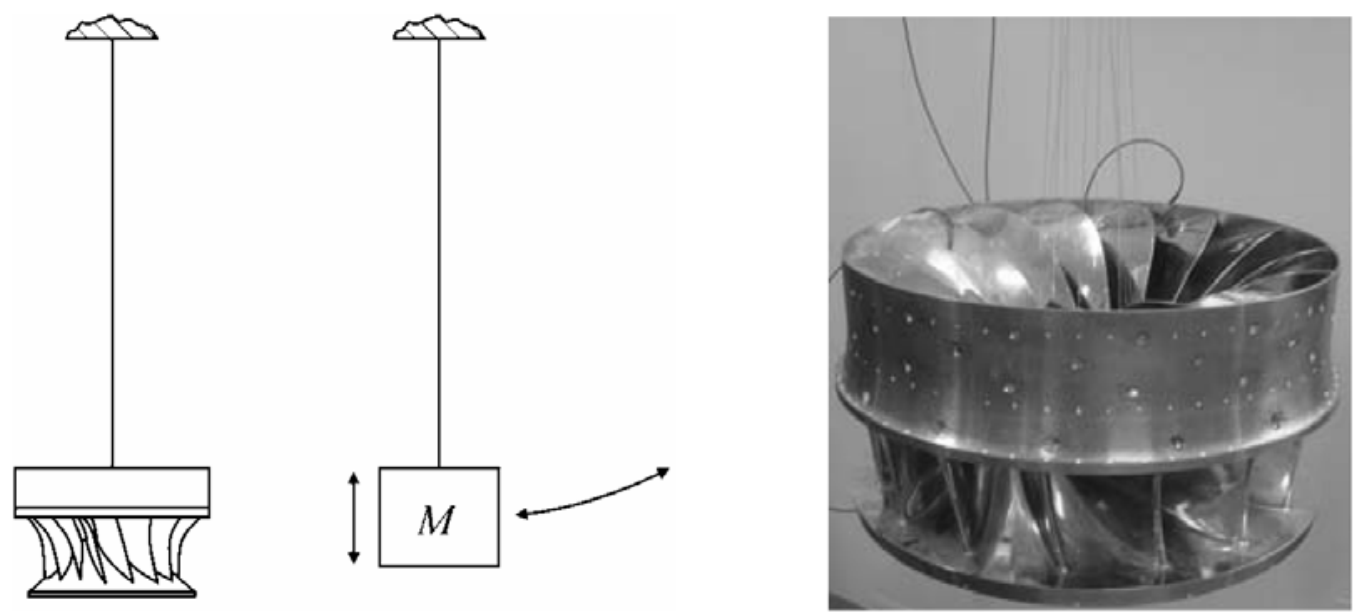

Fig. 4 Runner B - suspended runner for experimental setup 
An impulse force hammer with a steel impact tip has been used to excite the mechanical structure. The vibrations induced by the hammer impact have been measured by miniature accelerometers. For determining the natural frequencies and mode shapes the roving hammer method was applied. Further information can be found in 0 .

\section{Numerical modal analysis:}

For the numerical modal analysis in air and in water, runner B was modelled as one integral part neglecting the actual blade fixations. The unconstrained finite element model and the corresponding boundary conditions can be found in Fig. 5. The solid model consists of quadratic tetrahedral elements for the structure and acoustic elements for the fluid.

a)

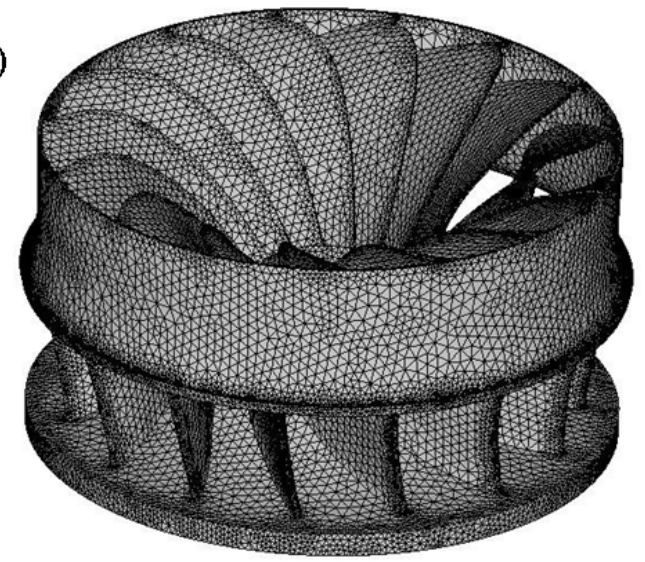

b)

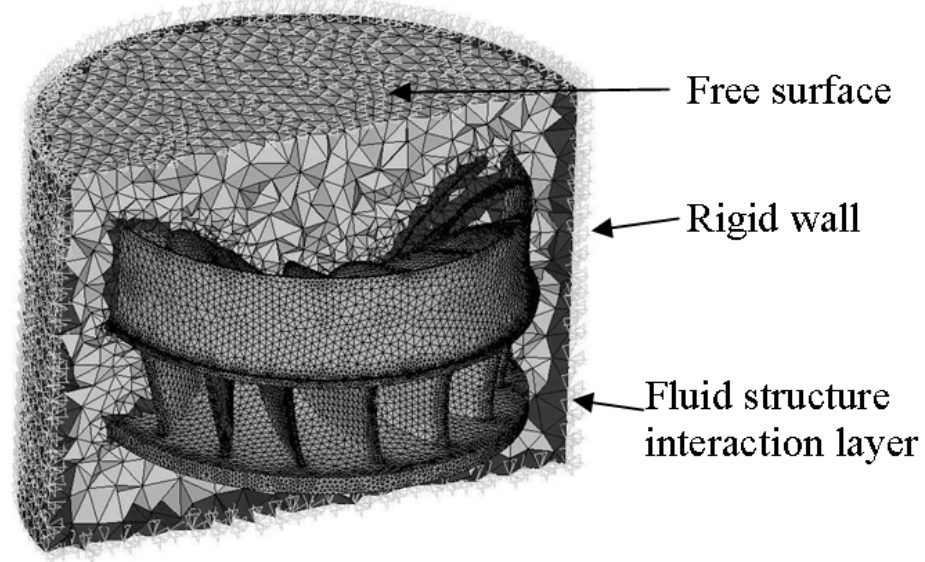

Fig. 5 Runner B - finite element model in a) air and b) water

A parameter study was carried out in order to identify the influence of several numerical and structural parameters such as material, size and geometrical details of the hub on the modal properties of the runner. A summary of the investigated parameters and the respective finite element models is listed in Table 2. Please note that the boundary conditions are the same, as described above except for the fixed boundary conditions which were here applied at the bolt circle.

Table 2: Description of finite element models for the parameter study

\begin{tabular}{|c|c|c|c|c|}
\hline Model & Scale & Material & Crown design & Environment \\
\hline B1 & Prototype & $\begin{array}{c}\text { Material of Prototype } \\
\left(\mathrm{E}=200 \mathrm{GPa}, \rho=7700 \mathrm{~kg} / \mathrm{m}^{3}\right)\end{array}$ & $\begin{array}{c}\text { Simplified } \\
(\text { without pressure relieving } \\
\text { holes and rips })\end{array}$ & Water \\
\hline B2 & Prototype & Material of Prototype & Simplified & Air \\
\hline B3 & Prototype & $\begin{array}{c}\text { Material of Model } \\
\left(\mathrm{E}=100 \mathrm{GPa}, \rho=8600 \mathrm{~kg} / \mathrm{m}^{3}\right)\end{array}$ & Simplified & Water \\
\hline B4 & Prototype & Material of Model & Simplified & Air \\
\hline B5 & Model & Material of Model & Simplified & Water \\
\hline B6 & Model & Material of Model & Original \\
\hline B7 & Model & Material of Model & Original & Water \\
\hline B8 & Model & Material of Model & \\
\hline
\end{tabular}

\subsection{Runner C - Setup and application of unsteady CFD and harmonic response analysis}

For the investigations in the second part of this study a high head Francis runner was chosen with higher specific speed and with higher exciting forces than the runners A and B investigated in the first part of the study.

In a Francis turbine the main exciting forces arise from the rotor stator interaction (RSI) between the wicket gate and the runner. Usually, this interaction is supposed to be a nearly harmonic process thereby justifying the application of harmonic response analysis. The most important frequency resulting from this process regarding fatigue is the basic mode or 1st harmonic of the excitation because of the usually highest energy content of the lowest mode. This frequency is the so-called wicket gate passing frequency which is the rotational frequency $f_{n}$ times the number of guide vanes. This frequency is characterised by a nodal diameter mode which is strictly dependent on the number of runner blades and number of guide vanes, 0 . The turbine under investigation consists of 17 runner blades, 28 guide vanes and 14 stay vanes which results in a nodal diameter mode of the travelling pressure wave of ND6. The corresponding exciting frequency is $28 * f_{n}$, the aforementioned wicket gate passing frequency. 


\section{CFD setup:}

Based on previous investigations and validation work of the CFD method for predicting rotor stator interaction in Francis turbines 0 and 0 the CFD model consists of a $360^{\circ}$-model of the spiral case, stay vanes, guide vanes and the runner blades, see Fig. 6. For simplification the stay vane ring is assumed to be symmetrical and the nose plate is being neglected. The 3D Navier Stokes equations are solved using the commercial software package CFX10, 0.

Boundary conditions: The flow rate of the operating point is prescribed at inlet, the outflow boundary condition is a constant pressure value averaged across the outlet region.

Spatial discretisation: All parts of the computational domain are discretised with a hexahedral grid, whereby the grid for the stay vanes consists of 1'136'000 nodes; the grid for the guide vanes consists of 2'256'000 nodes and the one for the runner of 2'653'000 nodes. Special attention is given to an accurate resolution of the boundary layer at the surfaces. For spatial discretisation a mostly second order accurate total variation diminishing scheme (TVD) scheme is used. Discretisation in time is done with a second order backward Euler scheme.

Turbulence model: Turbulent fluctuations are modelled with the standard k- model.

Convergence: The root mean square residuals have to be below 10-5, the maximum residuals have to be below 10-3 and the overall imbalances of mass and momentum have to be below 10-3. In addition, monitoring points are positioned in which the values of pressure and velocities are monitored during the course of the simulation. A simulation is qualified as converged only when these values do not change any more.

The CFD analysis was carried out for one full load operating point at model scale.
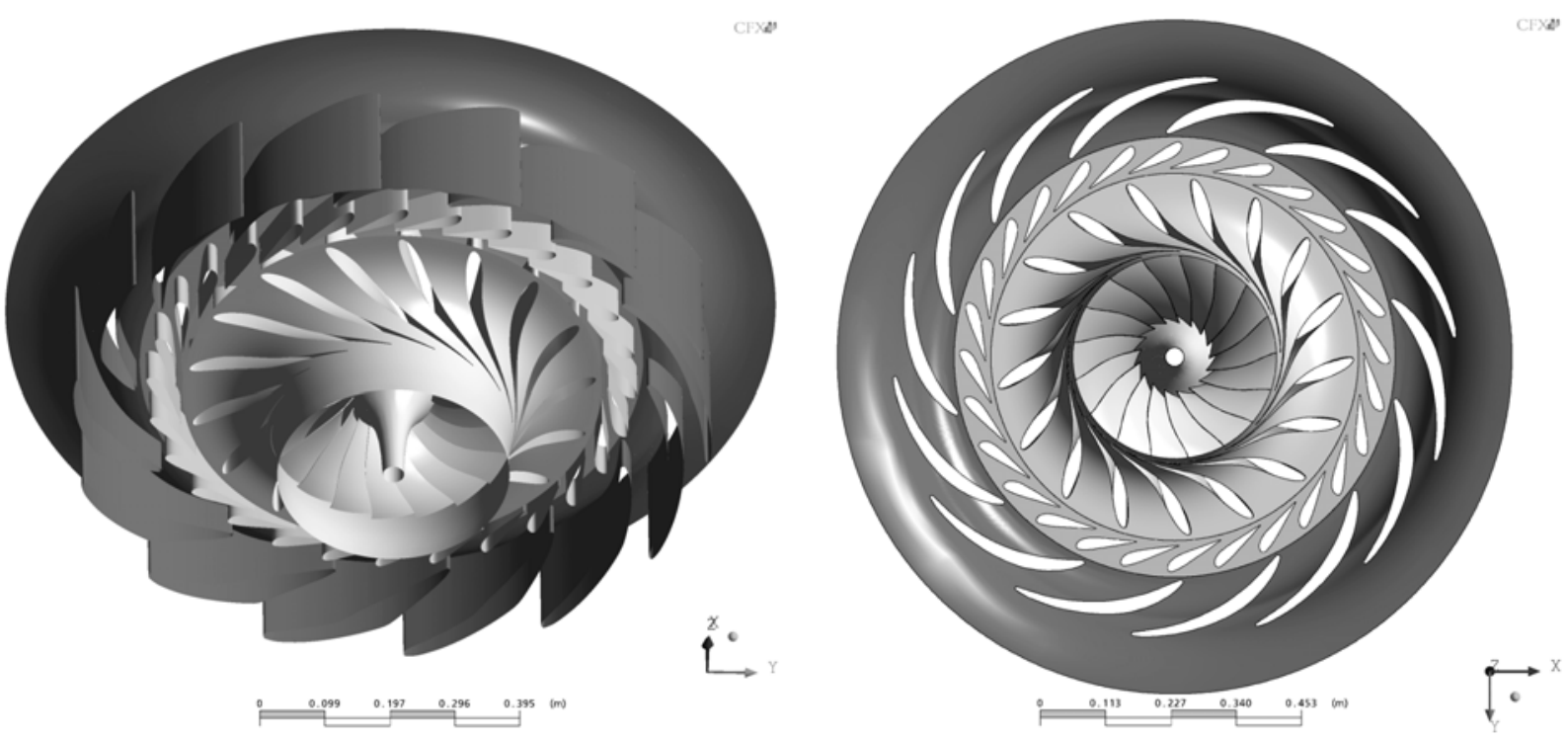

Fig. 6 CFD model of runner $\mathrm{C}$ for the unsteady analysis

Generally, the results of unsteady CFD analysis are in the time domain which is not the appropriate form for the following harmonic response analysis requiring amplitude and phase or real and imaginary inputs, respectively. Therefore, after completion of the unsteady CFD analysis, the calculated pressure values in the time domain are transferred into the frequency domain by means of a Fast Fourier Transformation (FFT). At the same time the model scale pressure values are transferred to prototype scale by means of the ratio of the net heads $\mathrm{H}_{\text {net,prototype }} / \mathrm{H}_{\text {net,model }}$.

From the results of the FFT the exciting frequencies and the corresponding nodal diameter mode from the phase angle can be identified. These values must comply with the values described above, i.e. ND6 with an exciting frequency of $28 * f_{n}$.

\section{Finite element setup:}

The finite element model and the corresponding boundary conditions for the harmonic response analysis can be found in

Fig. 7. The elements are chosen to be the same as for the modal analyses. In contrast to the finite element models of runners A and $\mathrm{B}$, the hub and band chamber geometry including the labyrinth gaps are taken into account. Rigid wall boundary conditions are considered for the stationary part. The pressure amplitudes and phase angles derived from the unsteady CFD analysis are applied in order to excite the structure with the proper ND mode. 

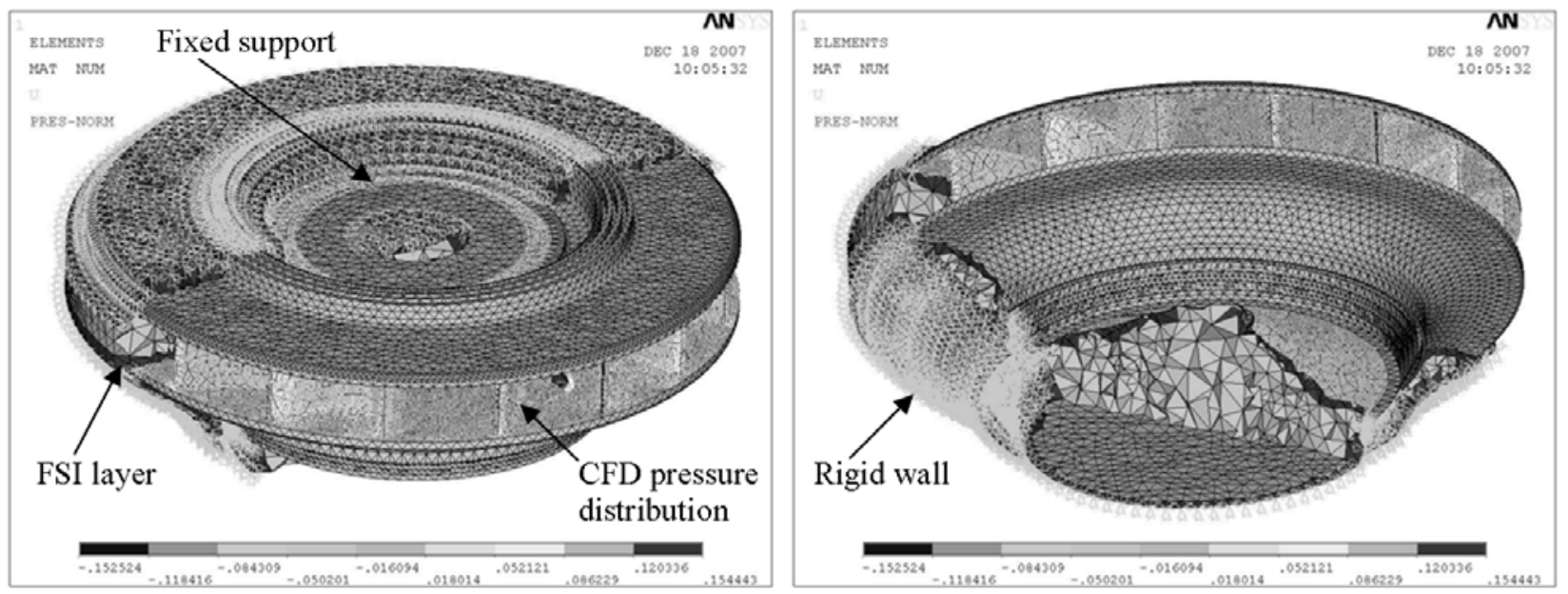

Fig. 7 Finite element model of runner $\mathrm{C}$ for the harmonic response analysis

\section{Results}

In the first two parts of the following paragraph, the findings of the experimental and numerical modal analyses are presented and compared. In the third part the results of the harmonic response analysis using CFD data are discussed.

\subsection{Runner A - Results and comparison of the modal analyses}

\section{Simulation and Experiment:}

Fig. 8 gives an overview of the results of the experimental and numerical modal analysis of runner A. The most striking issue here is the uncertainty of the geometry when a runner is casted and already altered by erosion and its impact on determining natural frequencies and mode shapes. This issue could be clearly demonstrated with the first comparison of simulation and experiment as shown in

Fig. 8a, left hand side. The diagram on the left shows the first comparison of the simulation of the ideal runner as it was originally designed which is in poor agreement with the measurements. After the first tests, the actual geometry of the runner was measured and a new CAD model was created. The results of the numerical modal analysis of the new geometry can be found in

Fig. 8b. Here, the results of the simulation comply very well with the results of the experimental modal analysis. 


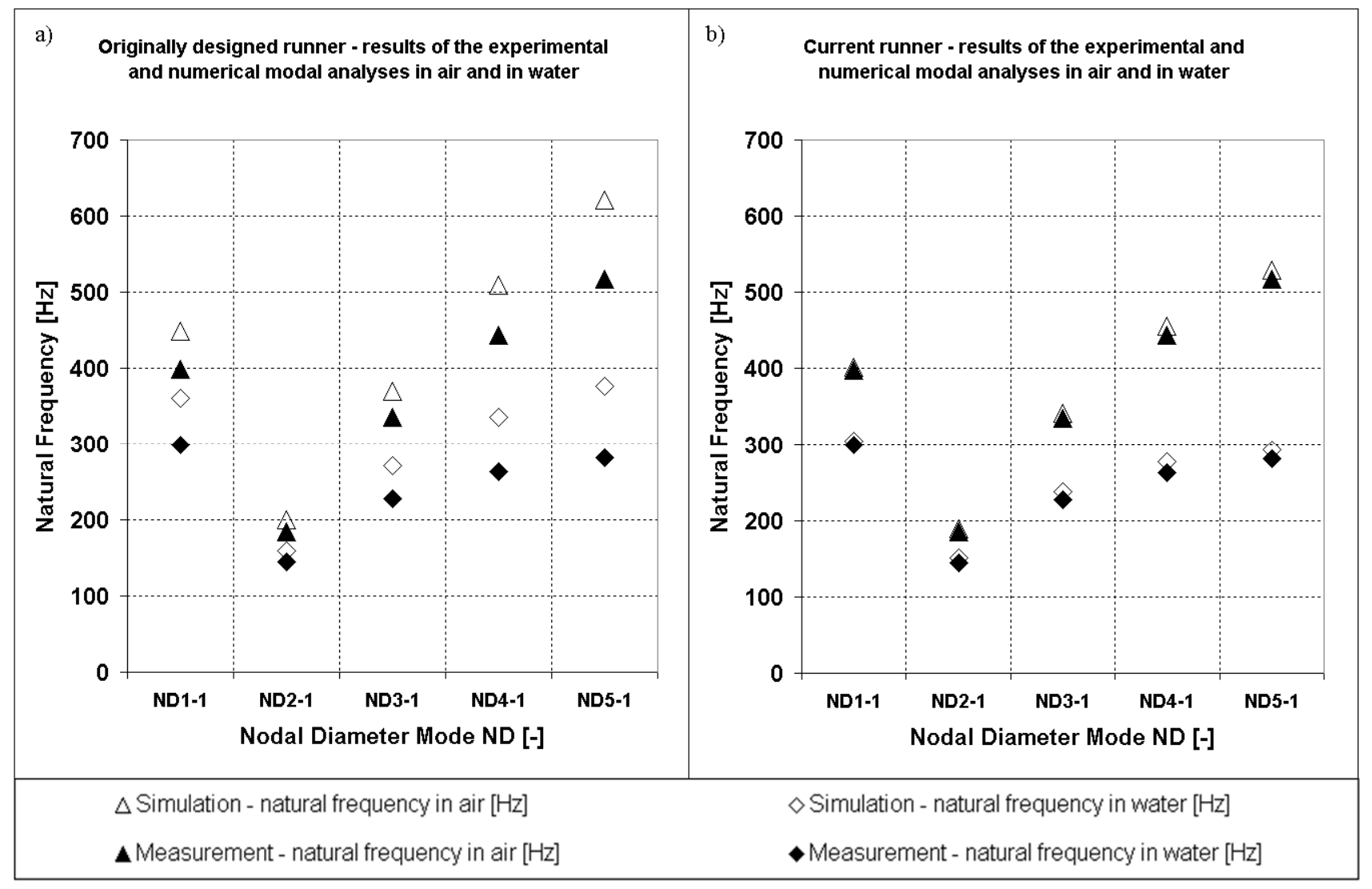

Fig. 8 Results of simulation and experiment on runner A; a) ideal runner geometry, b) actual runner geometry

\subsection{Runner B - Results and comparison of the modal analyses}

\section{Simulation and Experiment:}

The results of the experimental and numerical modal analysis on runner B are summarised in Table 3 and displayed in Fig. 9 which shows a considerable discrepancy of the frequencies between experiment and simulation for the lower nodal diameter modes, with a maximum occurring error of $15 \%$ in air and $12 \%$ in water. This is a result of the different blade fixations in the simulation compared to measurement which plays a more important role for the global runner modes, i.e. the lower nodal diameter modes $(\leq \mathrm{ND} 2-1)$. For higher nodal diameter modes (>ND2-1) the main part of the vibration occurs on the trailing edge. Therefore, the error for these modes is far smaller. Interestingly, for the FRR the discrepancy between measurement and simulation is far smaller than for the frequencies, with a maximum of $6 \%$ over the whole range which is an indication that the FRR is mainly a function of the blade geometry and not of the blade fixation.

Figure 9 also reveals the typical decreasing behaviour of the FRR with increasing ND mode which was also detected in 0. 
Table 3 Results of simulation and experiment on runner B

\begin{tabular}{|c|c|c|c|c|c|c|c|c|c|}
\cline { 2 - 10 } \multicolumn{1}{c|}{} & \multicolumn{2}{c|}{ Natural frequency in air } & \multicolumn{2}{c|}{ Natural frequency in water } & \multicolumn{2}{c|}{ FRR } \\
\hline $\begin{array}{c}\text { Runner } \\
\text { mode }\end{array}$ & $\begin{array}{c}\text { Measurement } \\
{[\mathrm{Hz}]}\end{array}$ & $\begin{array}{c}\text { Simulation } \\
{[\mathrm{Hz}]}\end{array}$ & $\begin{array}{c}\text { Error } \\
(\%)\end{array}$ & $\begin{array}{c}\text { Measurement } \\
{[\mathrm{Hz}]}\end{array}$ & $\begin{array}{c}\text { Simulation } \\
{[\mathrm{Hz}]}\end{array}$ & $\begin{array}{c}\text { Error } \\
{[\%]}\end{array}$ & $\begin{array}{c}\text { Measurement } \\
{[-]}\end{array}$ & $\begin{array}{c}\text { Simulation } \\
{[-]}\end{array}$ & $\begin{array}{c}\text { Error } \\
(\%)\end{array}$ \\
\hline ND0-1 & 658 & 753 & -13 & 568 & 635 & -10 & 0.86 & 0.84 & 3 \\
\hline ND1-1 & 1056 & 1122 & -6 & 643 & 674 & -5 & 0.61 & 0.60 & 1 \\
\hline ND2-1 & 511 & 602 & -15 & 365 & 417 & -12 & 0.71 & 0.69 & 4 \\
\hline ND3-1 & 801 & 857 & -7 & 420 & 445 & -6 & 0.52 & 0.52 & 1 \\
\hline ND4-1 & 869 & 933 & -7 & 404 & 421 & -4 & 0.46 & 0.45 & 3 \\
\hline ND5-1 & 965 & 959 & 1 & 383 & 397 & -4 & 0.40 & 0.41 & -3 \\
\hline ND6-1 & 979 & 965 & 1 & 365 & 379 & -4 & 0.37 & 0.39 & -4 \\
\hline ND7-1 & 989 & 965 & 3 & 355 & 369 & -4 & 0.36 & 0.38 & -6 \\
\hline
\end{tabular}

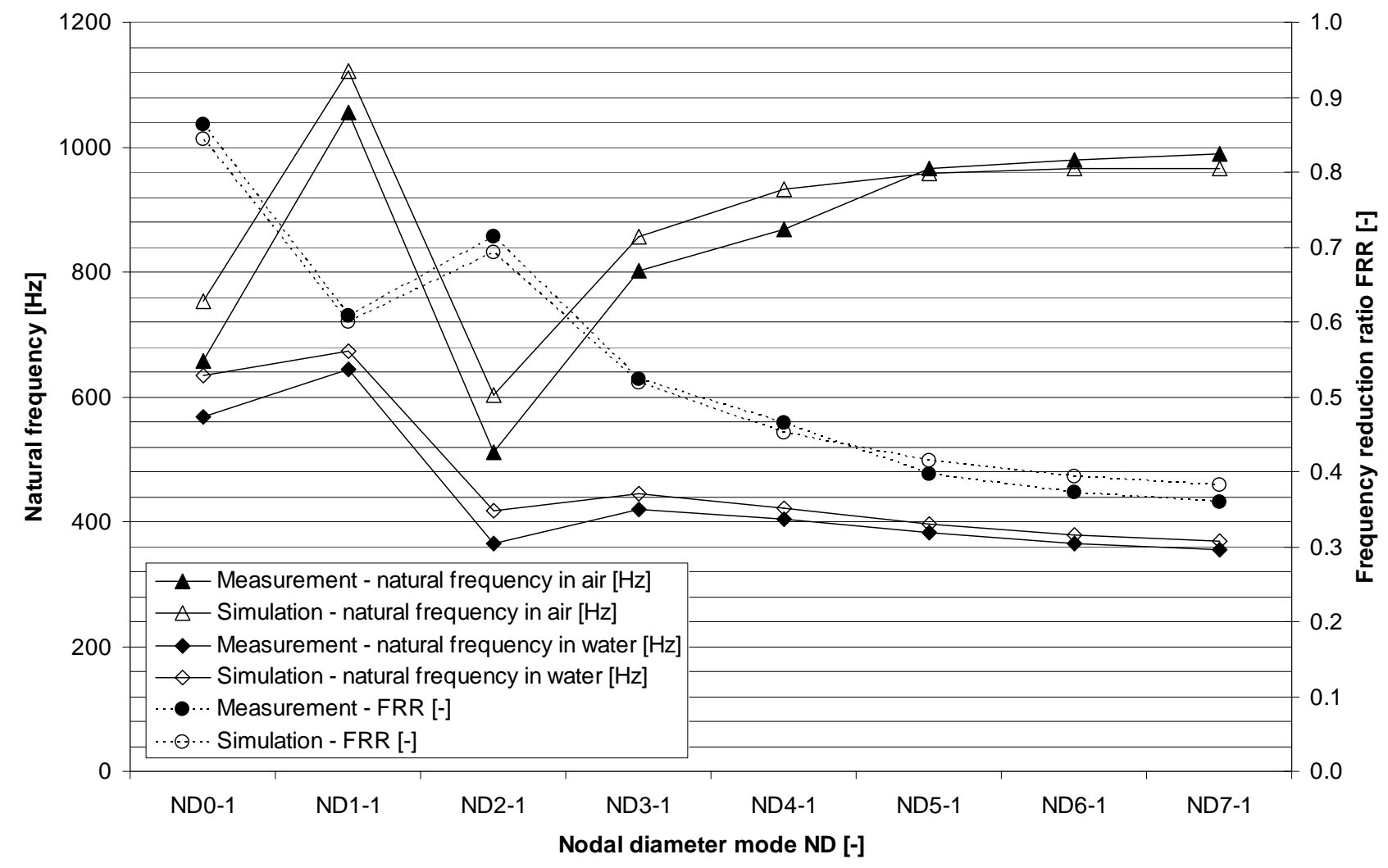

Fig. 9 Results of simulation and experiment on runner B

\section{Parameter study:}

In order to identify the influence of material and scale on the modal properties a parameter study was carried out, see Table 2. Fig. 10 shows the results of the numerical analysis both without surrounding water (variants B1, B3, B5 and B7) and with surrounding water (B2, B4, B6 and B8). In the lower part of the diagram the predicted natural frequencies are displayed for all 8 parameter variations showing the considerable influence of both material and scale and also of the crown geometry on the natural frequencies. Interesting is the upper part of the diagram which displays the results for the FRR. It confirms that the FRR are mainly a function of the blade geometry and are not affected by the investigated parameters material, scale and crown geometry. 


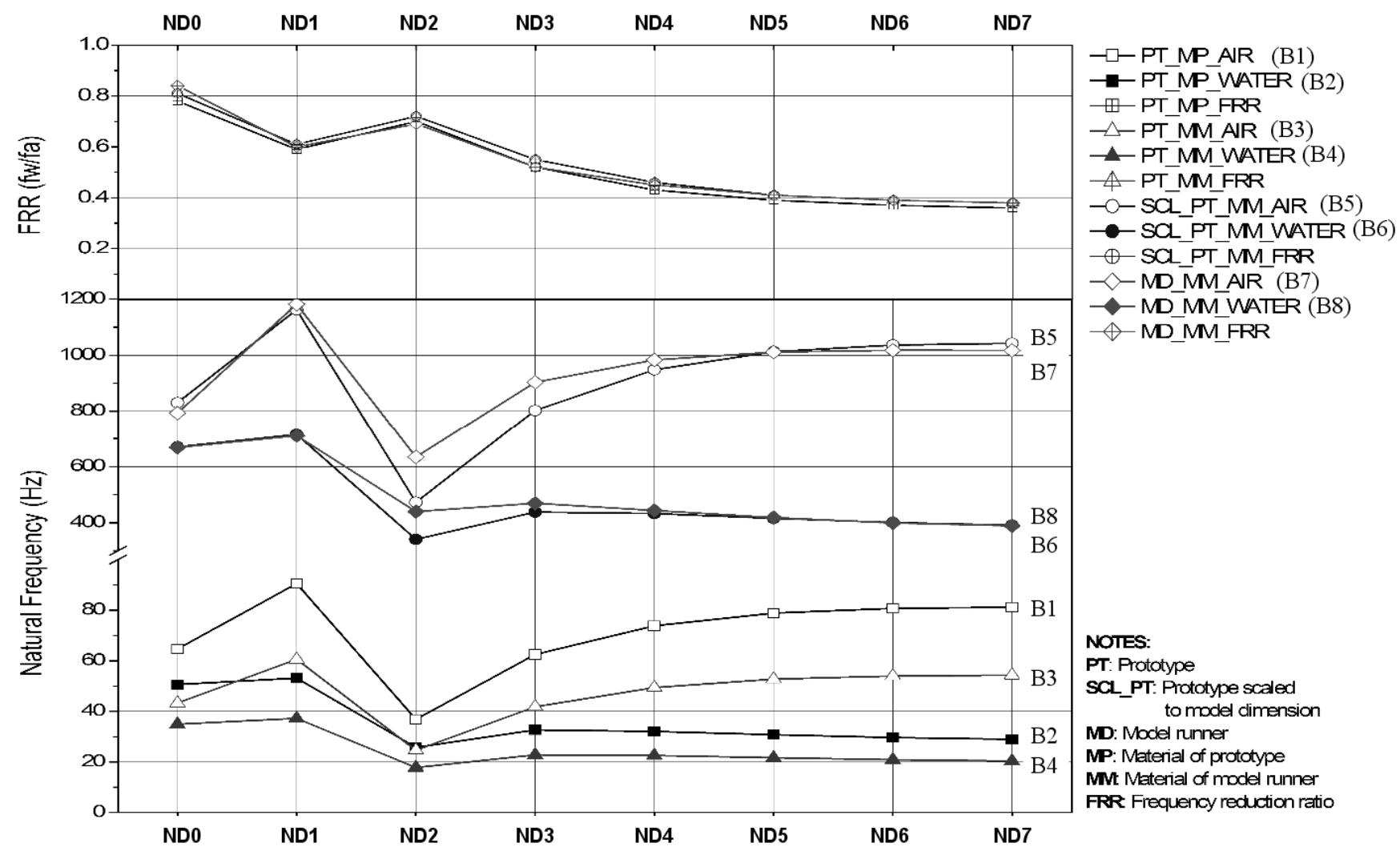

Fig. 10 Results of simulation and experiment on runner B; for details of the parameter variations please refer to Table 2.

From these results we conclude that geometrically similar blade profiles may have different natural frequencies but that at the same time the effect of water is similar for the different configurations leading to the same values of the frequency reduction ratio FRR. This newly gained insight will be useful in an early design stage when a complete modal analysis in water is too time consuming.

\subsection{Runner C - Results of the unsteady CFD and the harmonic response analysis}

\section{CFD results:}

Fig. 11 gives an overview of the pressure field predicted by the time dependent CFD simulation after being transformed into the frequency space by FFT. In the upper diagram it shows the maximum pressure amplitudes on the blade's mid plane. While the not marked peaks indicate the excitation of the guide vanes the ND modes acting on the runner are marked by black dots:

- The ND3 mode at $14 * f_{n}$ corresponds to the runner excitation due to the stay vane wakes.

- The ND6 mode at $28 * \mathrm{f}_{\mathrm{n}}$ corresponds to the wicket gate passing frequency.

- The ND5 mode at $56^{*} f_{n}$ is the second harmonic of the wicket gate passing frequency. 


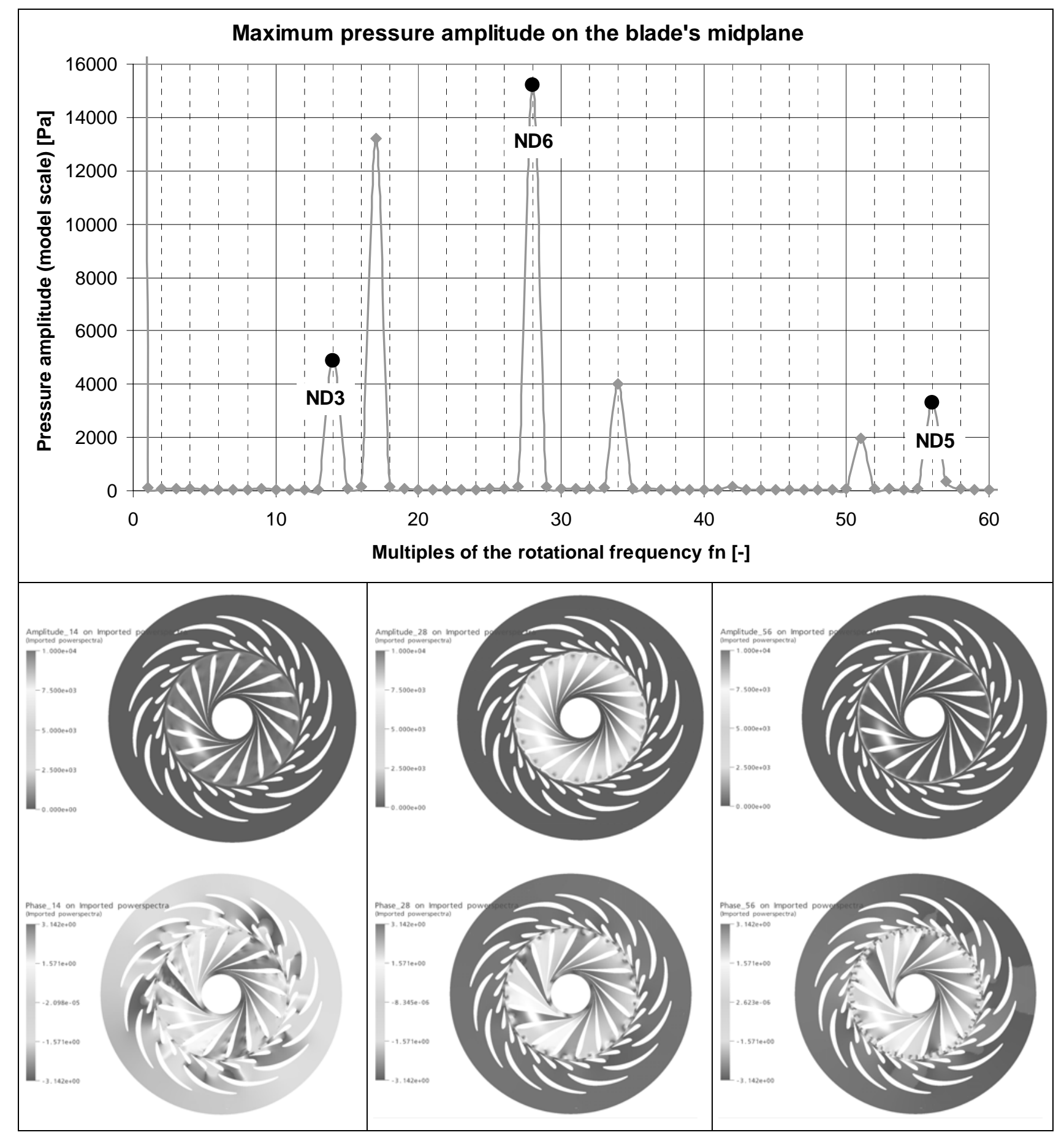

Fig. 11 Results of the FFT of the instationary CFD

The diagram in Fig. 11, also shows that the CFD prediction delivers the wicket gate passing frequency with ND6 mode and an exciting frequency of $28^{*} \mathrm{fn}$ as most important exciting mode in terms of rotor stator interaction (RSI) with the highest pressure amplitude. Thus, the CFD prediction is in accordance with the (analytical) deduction, given above.

\section{Harmonic response analysis:}

As the ND6 mode is found to be dominating, the pressure amplitudes and phase angles of mode ND6 resulting from the FFT serve as an input for the harmonic response analysis. Fig. 12 depicts the real part of the axial displacements for the resulting ODS. By showing the real part only, the ND6 mode can again be identified. Similarly, the real part of the stress amplitude, i.e. the 1st principal stress amplitude of the ODS is displayed in Fig. 13. Assessing the stresses acting on the runner requires the imaginary part to be considered, too. This can be done by plotting the calculated stress amplitudes at the point of interest versus the corresponding phase angle as shown in the diagram of Fig. 13. It can be seen that the stress maximum is almost correct with taking into account the real part only which is a characteristic of the relatively high degree of cyclic symmetry in connection with the high nodal diameter mode of the ODS. However, generally both the real and the imaginary part must be considered for stress evaluation. 


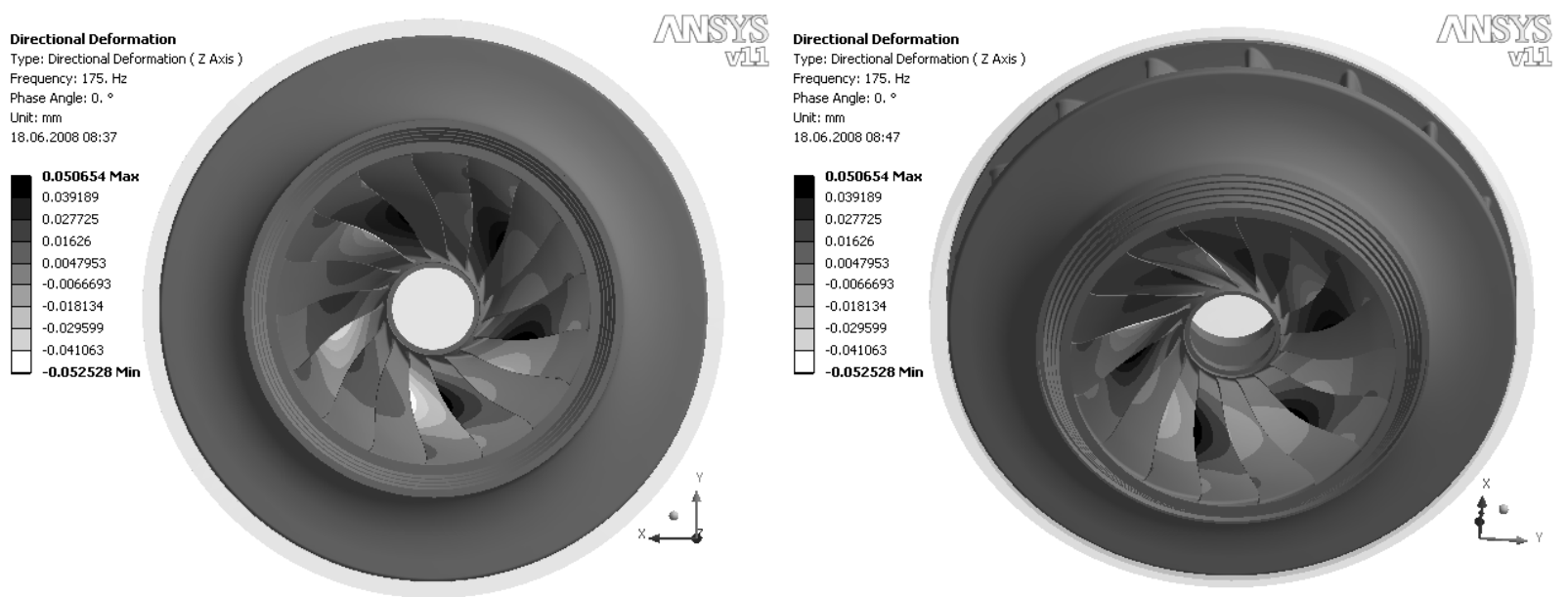

Fig. 12 Real part of the axial displacements for the ODS (ND6, 28* $f_{n}$ )

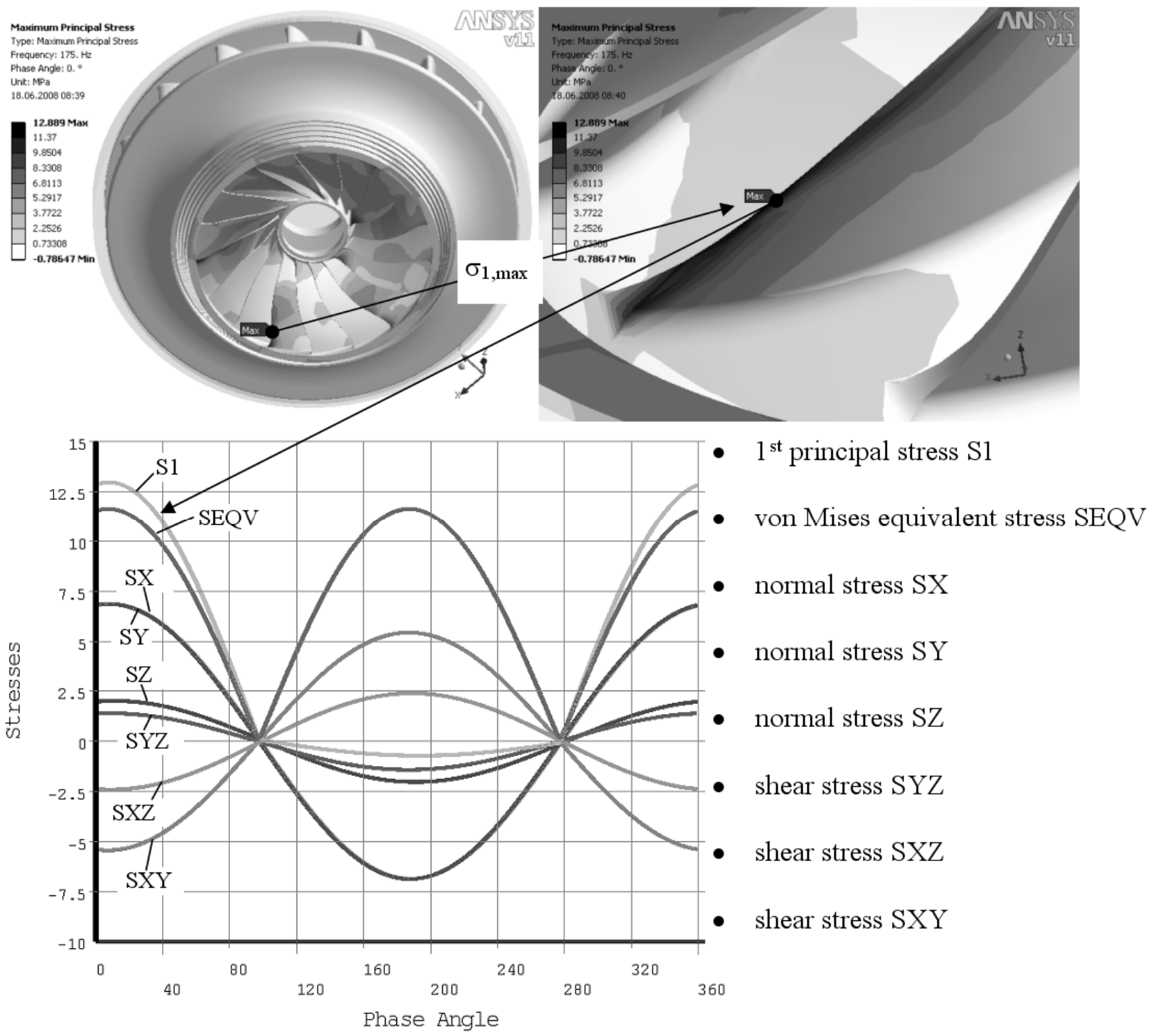

Fig. 13 Real part of the stress amplitude of the ODS (ND6, 28*f $\left.\mathrm{f}_{\mathrm{n}}\right)$

\section{Final Considerations}

Investigations of the structural properties of three different Francis turbine runners were presented and discussed with focus on the dynamic load due to rotor stator interaction. The numerical FEM analysis of mode shapes and natural frequencies is validated by comparison with measurement data. It is found to be a reliable and accurate prediction method which is useful for detailed analysis of structural properties of Francis runners and of the parameters influencing these properties. Such a parameter study is presented for a Francis runner. The study shows that the frequency reduction ratio (FRR) of a Francis runner is mainly determined 
by the blade geometry, that it is nearly independent of the crown geometry and fully independent of material and scale.

The results of the analysis so far show that the dynamic behaviour of the runner submerged in still water can be correctly described with finite element analysis. However, some influences on the dynamic behaviour have not been investigated in detail yet: Firstly, there is the influence of the seals and labyrinths. The closer the gap between two bodies the higher is the added mass effect and consequently, the lower is the natural frequency, see 0. Secondly, the investigations so far are all executed in still water, whereas the flowing fluid might have an additional influence. Thirdly, the damping has been neglected during this study. Damping is usually not of great importance for modal analysis but might be very important for forced vibration calculation especially in case the dominating natural frequency and the exciting frequency are close to each other.

In the second part of the study a harmonic response analysis is carried out for a Francis runner in order to gain the dynamic stresses which then can be used for fatigue assessment. Harmonic response analysis is based on the dynamic pressure amplitude field derived from a preceding instationary CFD analysis. With the CFD data fully utilised, the harmonic response analysis can be carried out for the frequencies of interest.

Some questions related to harmonic response analysis and dynamic stresses, respectively remain open: Firstly: Is there a size effect on dynamic stress behaviour? The CFD analysis is carried out at model scale but the interesting stresses regarding fatigue assessment have to be derived at prototype scale. Secondly: What is the influence of the flowing fluid and the damping? Thirdly: Is the assumption of a harmonic excitation sufficient to describe the effect of rotor stator interaction (RSI)? For low head runners, the distance between guide vane and runner blade is usually large leading to relatively weak exciting forces. In high head Francis runners, pumps and pump turbines, this gap is usually small causing higher exciting forces with a more pulse-like shape which shifts higher energy content to the higher harmonics. This might lead to the need of either the superposition of different harmonic response analyses with all important harmonics or of a transient analysis which, however, is today out of reach in terms of computational effort.

Further measurements will be done in order to clarify these questions. As immediate benefit from the research reported here simplified tools have been derived for the daily engineering process thereby meeting today's design requirements in order to obtain the requested lifetime of the turbines.

\section{Nomenclature}

\section{References}

[1] ANSYS Version 11 Documentation.

[2] X. Escaler, Q. Liang, C. Valero, E. Egusquiza, St. Lais, M. Sick, "Th. Weiss: Experimental Modal Analysis of a Francis Model Runner," Proceedings of the 24th IAHR Symposium on Hydraulic Machinery and Systems, October 27-31 2008, Foz do Iguassu, Brazil.

[3] M. Dubas, "On the excitations due to the periodic structure of turbomachines," Ingenieur-Archiv (Ing.-Arch.), vol. 54, 1984, pp. 413-426.

[4] M. Sick, St. Lais, W. Michler, P. Stein, "Th. Weiss: Numerical prediction of flow induced dynamic load in water turbines: recent developments and results," Proceedings of HYDRO 2007, Granada, Spain, October 2007.

[5] M. Keller, M. Sallaberger, "Modern hydraulic design of pump turbines," Proceedings of the International Seminar on Hydropower Plants, Vienna, Austria, November 22 - 24, 2006.

[6] CFX10 Theory Documentation, ANSYS, Harwell, U.K., 2005.

[7] Q.W. Liang, E. Egusquiza, X. Escaler, F. Avellan, "Modal Analysis on a Francis Turbine Runner Considering the Fluid Added Mass Effect," Proceedings of the IAHR Int. Meeting of WG on Cavitation and Dynamic Problems in Hydraulic Machinery and Systems, Barcelona, 28-30 June 2006.

[8] E: Naudascher, D. Rockwell, "Flow-induced vibration. An engineering guide,” Dover Publication Inc.,2005 